\begin{tabular}{|c|c|c|}
\hline Iso & $\begin{array}{c}\text { Bulletin of Pharmaceutical Sciences } \\
\text { Assiut University }\end{array}$ & \\
\hline 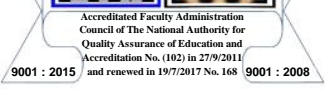 & $\begin{array}{c}\text { Website: http://bpsa.journals.ekb.eg/ } \\
\text { e-mail: bullpharm@aun.edu.eg }\end{array}$ & $\begin{array}{l}\text { BULL. PHARM. SCI. } \\
\text { Assiut Univ. }\end{array}$ \\
\hline
\end{tabular}

\title{
FLOATING IN-SITU RAFT FORMING LIQUID GASTRORETENTIVE DRUG DELIVERY SYSTEM CONTAINING POORLY WATER- SOLUBLE DRUG
}

\author{
Vaishali Joshi and Rajendra Awasthi ${ }^{*}$ \\ Amity Institute of Pharmacy, Amity University Uttar Pradesh, Sec. 125, Noida, 201303, Uttar \\ Pradesh, India
}

\begin{abstract}
Present work was aimed to develop a liquid in-situ raft forming floating gastroretentive system of repaglinide using gellan gum, pectin, and sodium alginate. The formulations were characterized in terms of compatibility of drug-excipient by Fourier transform infrared, drug content, effect of processing parameters on physical form of drug (crystalline or amorphous) by $X$-ray diffraction analysis, thermal behaviour by differential scanning calorimetry, and in-vitro drug release study. The results confirm no interaction between the drug-excipients and fusion of drug crystals within the polymer matrix in amorphous form. The gel raft-floated for more than 24 hrs.. All the formulations showed instantaneous gelation within 30 seconds in $0.1 \mathrm{~N} \mathrm{HCl}$ (pH 1.2). Formulation containing gellan gum $(500 \mathrm{mg})$, pectin $(500 \mathrm{mg})$, and glycerol monostearate $(500 \mathrm{mg})$ released $21 \%$ of the drug in first $4 \mathrm{hrs}$., $69 \%$ in $6 \mathrm{hrs}$. and reached $97 \%$ in $7 \mathrm{hrs}$. Without gellan gum, 35\% of the drug was released in the first 2 hrs. and reached $90 \%$ in 4 hrs. Based on these results it is suggested that the incorporation of drug into the liquid in-situ raft forming floating system may be an appropriate strategy to improve the dissolution profile of poorly soluble drugs.
\end{abstract}

\section{INTRODUCTION}

Oral route is the most convenient and preferred route for drug administration due to patient compliance. For maintaining drug concentration in the required therapeutic range, a conventional system needs to administer several times a day. This may cause considerable fluctuation in plasma drug concentration ${ }^{1}$. This has increased the demand for the development of controlled release drug delivery systems. An approximately planned controlled released drug delivery system can be a promising approach to overcome these two issues. The target of controlled release drug delivery incorporates two significant aspects namely spatial placement and temporal delivery of the drug. Spatial placement identifies with focusing on medication to a particular organ or tissue, while temporal conveyance alludes to controlling the rate of drug delivery to the target tissue ${ }^{2}$. However, a controlled release system may offer limited benefits for the drugs that have a narrow therapeutic window in the stomach or upper small intestine.

To increase the oral bioavailability of such drugs, the gastric residence time of formulation needs to be increased ${ }^{3}$. These systems may offer better alternative for the treatment of disease using existing drug molecules. Gastroretentive floating systems (GRFS) have been reported to overcome the bioavailability limitation of the drugs due to their poor absorption from the stomach or upper small intestine $^{4}$. An optimum gastroretentive floating system is one which is retained in the stomach for prolonged time against all the physiological barriers like contractions, crushing, grinding, and peristaltic waves in the stomach, exhibit controlled drug release in acidic envirnment and finally metabolized ${ }^{5-7}$. Various techniques include floating in-situ raft forming drug dosage systems have been proposed to increase 
the gastric residence time ${ }^{8}$. The structure engaged with the raft formation recalls the arrangement of viscous cohesive gel and expands as a layer on the top of gastric fluid. This raft floats on gastric fluid because of the low mass thickness made by the course of action of carbon-di-oxide 9 . The system remains in the stomach without influencing gastric discharging rate for a deferred timeframe ${ }^{10}$. These systems are fluids or dispersions at room temperature undergo through gelation when interacted with body fluids containing particles or because of $\mathrm{pH}$ change. These frameworks show a unique property of either temperaturedependent or cation actuated gelation, which assurances maintained and site explicit medication conveyance ${ }^{11}$. The formed gels stay intact inside the stomach for a few hours bringing about prolonged or delayed medication conveyance in the upper part of gastrointestinal tract ${ }^{12}$. However, the success of these systems depends on the availability of sufficient fluid volume and acidic environment within the stomach ${ }^{13}$.

Diabetes is a congregation of metabolic sickness characterized by hyperglycemia due to imperfections in insulin discharge, insulin activity, or both. The persistent hyperglycemia is related to long-duration harm, dysfunction, and collapse of different organs, particularly kidneys, heart, eyes, nerves, and veins. Rapid absorption of the drug and maintenance of dose for a prolonged time is the basic requirement to control blood glucose level in diabetic patients $^{14}$.

Repaglinide (2-ethoxy-4-[2-[[(1S)-3methyl-1-(2-piperidin-1-ylphenyl) butyl] amino]-2-oxoethyl] benzoic acid) is an oral antihyperglycemic specialist utilized for the treatment of non-insulin-dependent diabetes mellitus (Figure 1). It belongs to the meglitinide class of short-acting insulin secretagogues, which act by binding to $\beta$ cells of the pancreas to invigorate insulin discharge ${ }^{15,16}$. The elimination half-life of repaglinide is $1 \mathrm{hr}$. The mean absolute bioavailability is $56 \%$ when repaglinide is given with food. It has low water solubility (34 $\mu \mathrm{g} / \mathrm{mL}$ at $37^{\circ} \mathrm{C}$ ) and high lipophilicity $(\log \mathrm{P}=$ $3.97)^{17}$.

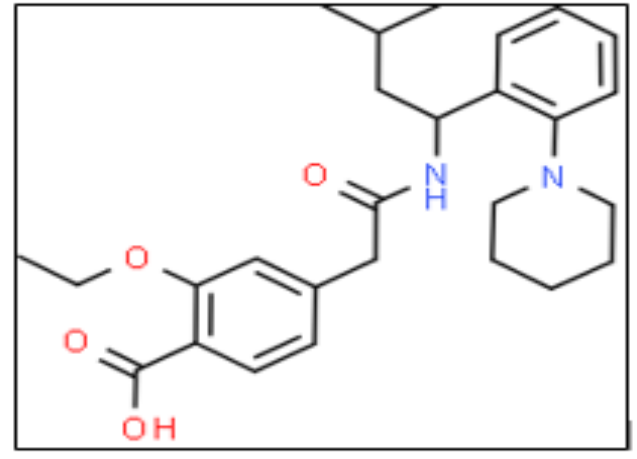

Fig. 1: Chemical structure of repaglinide

The purpose of this study is to explore liquid in-situ raft forming gastroretentive system for the controlled delivery of repaglinide. To achieve this objective, repaglinide containing liquid in-situ raft forming gastroretentive system was synthesized using sodium alginate, gellan gum, pectin, and glycerol monostearate. The effect of various polymer types and polymer concentration were examined. The synthesized liquid in-situ raft forming gastroretentive system was subsequently characterized for drug-excipient interaction study, X-ray diffraction study, thermal analysis, drug content, in-vitro gelling capacity, buoyancy, viscosity measurement, and in-vitro drug release profile.

\section{MATERIAL AND METHODS}

\section{Materials}

Repaglinide was received as a gift sample from Dr. Reddy's Laboratories, Hyderabad, India. Gellan gum was purchased from Sisco Research Laboratories Pvt. Ltd., Maharashtra, India. Pectin (DE 28-45\%) was purchased from Krishna Pectins Pvt. Ltd., Maharashtra, India. Sodium alginate and glycerol monostearate (GMS) were purchased from Central Drug House (P) Ltd., New Delhi, India. Sodium methylparaben was purchased from Arora \& Co., Delhi, India. Calcium carbonate was purchased from Sisco Research Laboratories Pvt. Ltd., Maharashtra, India. Sodium citrate was purchased from Thermo Electron LLS India Pvt. Ltd., Mumbai, India.

\section{Preparation of repaglinide GRFS}

Sodium alginate (a chelating agent) was dispersed in deionized water under stirring. In another beaker, gellan gum was added to 
deionized water containing sodium citrate. Both the solutions were mixed using a magnetic stirrer (REMI Elektrotechnik Limited, Mumbai, India) and GMS was added. The temperature was maintained at $90^{\circ} \mathrm{C}$. After cooling to $40^{\circ} \mathrm{C}$, pectin solution containing calcium carbonate and repaglinide was added with consistent stirring till the homogenous thick polymeric solution was obtained. Sodium methylparaben was added to the homogenous thick drug containing polymeric solution (Table 1). The formulation was degassed using a sonicator (Life Care Equipments Private Limited, Mumbai, India) ${ }^{18-20}$.

\section{Determination of drug content}

Drug content was determined by dissolving ten milliliters of formulation in 50 $\mathrm{mL}$ of methanol. The mixture was kept aside for $24 \mathrm{hrs}$. with intermittent stirring using a magnetic stirrer for complete extraction of drug from the polymeric system. After $24 \mathrm{hrs}$., the mixture was filtered through Whatman filter paper. The filtrate was analyzed spectrophotometrically at $244 \mathrm{~nm}$ using a UV spectrophotometer (3200, Labindia, Mumbai, India) to estimate the content of repaglinide in the sample ${ }^{21}$.

\section{Determination of in-vitro buoyancy}

The floating behaviour was recorded by introducing $2 \mathrm{~mL}$ of the GRFS into $100 \mathrm{~mL}$ of $0.1 \mathrm{~N} \mathrm{HCl}(\mathrm{pH} 1.2)$ in a $100 \mathrm{~mL}$ measuring cylinder. The time taken by the formulation to come back to the surface of the medium was recorded as buoyancy lag time (BLT). The time till which the formulation remained on the surface of the medium was recorded as total floating time ${ }^{11 \& 18 \& 20 \& 22}$.

\section{Determination of in-vitro gelling capacity}

Two milliliters of the formulation was carefully positioned into a measuring cylinder. Six milliliters of $0.1 \mathrm{~N} \mathrm{HCl}(\mathrm{pH} 1.2)$ was added gradually, and the gelation was accessed visually. The gelling capacity was scored in three categories (gels after couple of moments and dispersed rapidly, quick gelation and remains for $12 \mathrm{hrs}$., and quick gelation and remains for more than $12 \mathrm{hrs}$.) dependent on gelation time and period for which formed gel remained $^{18 \& 19 \& 22}$.

\section{Drug-excipient interaction study}

A drug-excipient interaction study was carried out using a Fourier transform infrared (FTIR) spectrophotometer (IR affinity-1, Shimadzu, Japan $)^{23}$. The FTIR spectral data of repaglinide and formulation $\mathrm{F} 1$ were taken for the determination of potential molecular interactions between the drug and excipients. The samples were gently triturated with $\mathrm{KBr}$ powder and compacted into a disc using a $\mathrm{KBr}$ press at 10 tons. The sample scanning was carried out from 4000 to $400 \mathrm{~cm}^{-1}$ at a resolution of $4 \mathrm{~cm}^{-1}$.

Table 1: Composition of liquid in-situ raft forming gastroretentiv system (for $100 \mathrm{~mL}$ )

\begin{tabular}{|l|c|c|c|c|c|c|c|c|c|}
\hline \multirow{2}{*}{ Ingredients (mg) } & \multicolumn{9}{|c|}{ Formulation code } \\
\cline { 2 - 11 } & $\mathbf{F 1}$ & $\mathbf{F 2}$ & $\mathbf{F 3}$ & $\mathbf{F 4}$ & $\mathbf{F 5}$ & $\mathbf{F 6}$ & $\mathbf{F 7}$ & $\mathbf{F 8}$ & F9 \\
\hline Repaglinide & 250 & 250 & 250 & 250 & 250 & 250 & 250 & 250 & 250 \\
\hline Gellan gum & 500 & 0 & 250 & 500 & 1000 & 500 & 0 & 1000 & 750 \\
\hline Pectin & 500 & 250 & 250 & 500 & 750 & 750 & 0 & 1000 & 1000 \\
\hline Sodium alginate & 1500 & 1500 & 1500 & 1500 & 1500 & 1500 & 1500 & 1500 & 1500 \\
\hline GMS & 500 & 250 & 250 & 1000 & 750 & 750 & 0 & 1000 & 1000 \\
\hline Sodium methyl paraben & 200 & 200 & 200 & 200 & 200 & 200 & 200 & 200 & 200 \\
\hline Calcium carbonate & 250 & 250 & 250 & 250 & 250 & 250 & 250 & 250 & 250 \\
\hline Sodium citrate & 250 & 250 & 250 & 250 & 250 & 250 & 250 & 250 & 250 \\
\hline
\end{tabular}




\section{X-ray diffraction study}

To analyze the physical form of the drug in the optimized formula, the X-ray diffractograms of pure repaglinide and formulation F1 were recorded by X-ray powder diffractometer (PW 3040/60 Xpert PRO, Panlytical, Netherlands). The X-ray diffraction patterns were recorded using $\mathrm{Cu} \mathrm{K} \alpha$ radiations $(\lambda=1.5405980 \AA)$, a voltage of $40 \mathrm{kV}$, and a current of $30 \mathrm{~mA}$. The samples were analyzed over 5-90 $2 \theta$ range with a scan step size of 0.02 and $0.50 \mathrm{~s} / \mathrm{step}^{5}$.

\section{Thermal analysis}

Thermograms of pure repaglinide, sodium alginate, gellan gum, pectin, and formulation F1 were produced by differential scanning calorimeter (DSC Q20 V24.11 Build 124 instrument equipped with Universal V4.5A TA Instruments software). Zinc $\left(419.5^{\circ} \mathrm{C}\right)$, tin $\left(232^{\circ} \mathrm{C}\right)$, and indium $\left(156^{\circ} \mathrm{C}\right)$ were used as internal standards to calibrate the instrument. Accurately weighed samples were placed into a $40 \mathrm{~mL}$ aluminum pan. The probes were heated upto $400^{\circ} \mathrm{C}$ at a rate of $10 \mathrm{~K} / \mathrm{min}$ under nitrogen atmosphere ${ }^{23}$.

\section{Viscosity measurement}

Viscosity measurements of formulation F1 (liquid and raft) were carried out using a Brookfield R/S Plus Rheometer (cone and plate model). The measuring system used was C-25 Din. The study was carried out at an angular velocity of $10,20,30,40,50$, and $60 \mathrm{rpm}$ and corresponding readings were recorded. Brookfield Rheo-2000 V2.8 software was used for the measurement of the rheological behaviour $^{24,25}$.

\section{In-vitro drug release study}

Repaglinide release from the liquid floating raft formulations (formulation F1, F2, and F3) was determined using a USP dissolution test apparatus (type II) (TDT06L, Electrolab, Mumbai, India) at $50 \mathrm{rpm}$ in $900 \mathrm{~mL}$ of $0.1 \mathrm{~N} \mathrm{HCl}(\mathrm{pH} \mathrm{1.2)}$. The temperature of dissolution fluid was maintained at $37^{\circ} \mathrm{C} \pm$ $0.5^{\circ} \mathrm{C}$. A measured amount of the formulation equivalent to $50 \mathrm{mg}$ repaglinide was added carefully to the dissolution vessel using a disposable syringe. The samples were $(5 \mathrm{~mL})$ withdrawn at each $30 \mathrm{~min}$ interval till $7 \mathrm{hrs}$. The sink condition was maintained by adding 5
$\mathrm{mL}$ of fresh dissolution fluid (maintained at the same temperature) after each withdrawal. The samples were filtered through a Whatman filter paper and analyzed using a UV spectrophotometer (3200, LabIndia, Mumbai, India). The sample analysis was carried in triplicate ${ }^{18 \& 19 \& 22}$. A graph of percentage cumulative drug released against time was plotted to access the dissolution profile of repaglinide from the developed floating raft formulations.

The in-vitro drug release data was statistically analyzed by two-way analysis of variance (ANOVA) followed by Tukey test using Graph Pad software (La Jolla, CA). The $p$ value of $<0.0001$ was considered statistically significant.

\section{RESULTS AND DISCUSSION}

\section{Drug Content}

Drug content was determined by UV spectrophotometric method. Drug content was found to be between $87.93 \pm 0.58 \%$ and 97.15 $\pm 0.66 \%$ (Table 2). The maximum percentage of drug content i.e. $97.15 \pm 0.66 \%$ is observed in case of formulation F1. The difference in the drug content among different formulations could be due to the difference in formulation viscosity associated with the polymer type and concentration used.

\section{In-vitro buoyancy}

In presence of gastric fluid, calcium carbonate delivered calcium ion and carbon dioxide gas. The calcium ion interacted with alginate and gellan gum to form gel like consistency. Once the liquid formulation added to $0.1 \mathrm{~N} \mathrm{HCl}(\mathrm{pH} \mathrm{1.2)}$, initially it sank to the bottom of the medium. At that point, the carbon-di-oxide was generated, and the gel moved up and was kept buoyant on the surface of the medium due to the entrapment of carbon dioxide within the gel network (Figure 2). The time that the formulation took to move from the bottom of the medium to its surface (buoyancy lag time) and the time that the formulation persisted on the medium surface (duration of floating) were recorded. The gel raftmaintained floating for more than $24 \mathrm{~h}$, except formulation F2 and F7. Formulation F2 was buoyant for about $12 \mathrm{hrs}$., which could be due to the low viscosity of the formulation at low 
polymer concentration. Formulation F7 did not contained pectin, gellan gum, and GMS, and the formed gel got dissolved quickly. Due to this, the entrapped carbon-di-oxide released quickly, and the formulation sank to the bottom after $6 \mathrm{~h}$ (Table 2). From experimental trials, it was observed that the formulation containing calcium carbonate had better floating ability than the formulation containing sodium carbonate (data not shown). The concentration of gellan gum, pectin and calcium carbonate influenced floating lag time. Floating lag time was reduced with an increase in calcium carbonate concentration. The increased concentration of gellan gum and pectin increased floating lag time and decreased floating duration.

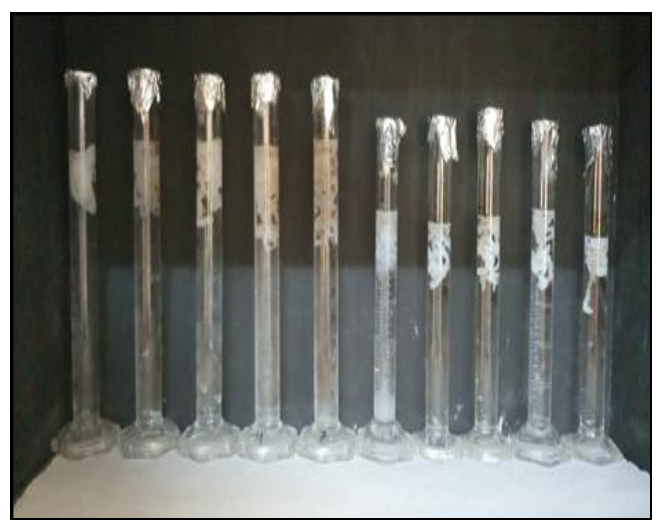

Fig. 2: Results of in-vitro buoyancy study.

\section{In- vitro gelling capacity}

All the formulations showed rapid gelation (within $30 \mathrm{sec}$ ) in $0.1 \mathrm{~N} \mathrm{HCl}(\mathrm{pH} 1.2)$ (Table 2 and Figure 3). Formulations without gellan gum with low level or without pectin showed quick gelation, but dissolves within 8 h. In case of formulation containing gellan gum and pectin at lower level showed quick gelation that was remained for $>12 \mathrm{hrs}$. GMS also had a significant role in gelling of the formulation. Formulations containing GMS at moderate of high concentration showed good gelling property for more than 24 hrs. Formulation containing calcium carbonate gelled more instantaneously than the formulation containing sodium carbonate (data not shown). Calcium carbonate present in the formulation as insoluble dispersion becomes soluble in an acidic medium and releases calcium ions leading to the gelation of formulation. Further, the divalent ions $\left(\mathrm{Ca}^{++}\right)$can make a stronger gel than that of monovalent ions $\left(\mathrm{Na}^{+}\right)$. Additionally, at a higher concentration of calcium carbonate a stronger gel was formed whereas a weak gel was formed at a low concentration of calcium carbonate ${ }^{20}$. The high polymer concentration and calcium carbonate mixture resulted in an adequate gel strength when pressed with a pair of forceps, indicating that the gel can withstand the peristaltic movement in the stomach. Thus, the developed system is expected to have a longer residence time than that of oral solutions of repaglinide.

Table 2: Results of drug content, gelation, buoyancy lag time, and floating time of repaglinide containing GRFS.

\begin{tabular}{||c|c|c|c|c||}
\hline $\begin{array}{c}\text { Formulation } \\
\text { code }\end{array}$ & $\begin{array}{c}\text { Drug content } \\
(\%)\end{array}$ & $\begin{array}{c}\text { Gelation } \\
\mathbf{( p H ~ 1 . 2 )}\end{array}$ & $\begin{array}{c}\text { Buoyancy lag } \\
\text { time (sec) }\end{array}$ & $\begin{array}{c}\text { Floating time } \\
\text { (h) }\end{array}$ \\
\hline F1 & $97.15 \pm 0.66$ & +++ & 37 & $>24$ \\
\hline F2 & $96.55 \pm 1.40$ & + & 13 & $>12$ \\
\hline F3 & $96.12 \pm 1.21$ & ++ & 20 & $>24$ \\
\hline F4 & $89.33 \pm 1.54$ & +++ & 63 & $>24$ \\
\hline F5 & $89.37 \pm 1.04$ & +++ & 91 & $>24$ \\
\hline F6 & $88.51 \pm 2.51$ & +++ & 69 & $>6$ \\
\hline F7 & $88.22 \pm 0.39$ & ++ & 3 & $>24$ \\
\hline F8 & $89.47 \pm 0.72$ & +++ & 105 & $>24$ \\
\hline F9 & $87.93 \pm 0.58$ & +++ & 89 & \\
\hline
\end{tabular}

+ quick gelation but dissolves within $8 \mathrm{~h},++$ quick gelation and remained for $>12 \mathrm{~h},+++$ quick gelation and remained for $>20 \mathrm{~h}$ 


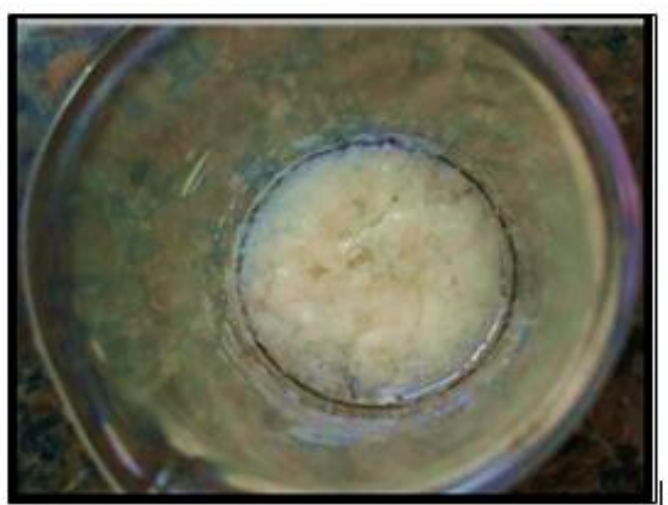

Fig. 3: Gel formation of GRFS in presence of $0.1 \mathrm{~N}$ $\mathrm{HCl}(\mathrm{pH} 1.2)$.

\section{Drug-excipient interaction study}

To check the compatibility of the drug with different excipients, the FTIR spectra of pure drugs and blend of the drug and excipients were taken (Figure 4). The FTIR spectrum of repaglinide revealed presence of $\mathrm{N}-\mathrm{H}$ stretching vibration at $3306.73 \mathrm{~cm}^{-1}$, carbonyl group $\left(1606.59,1634.56\right.$, and $1686.63 \mathrm{~cm}^{-1}$, C$\mathrm{H}$ stretching $\left(2934.0 \mathrm{~cm}^{-1}\right), \mathrm{N}-\mathrm{H}$ bending $\left(1634.56 \mathrm{~cm}^{-1}\right)$, aromatic ring $\left(1566.02 \mathrm{~cm}^{-1}\right)$, 1428.19-1499.91 cm $\mathrm{cm}^{-1}$ (C-O stretching), CN stretching at 1040.52, 1090.67, 1148.53, and $1176.50 \mathrm{~cm}^{-1}, \mathrm{CH}$ bending at $1449.41 \mathrm{~cm}^{-1}$ and
$\mathrm{CH}$ stretching at 2852.52, 2866.02, 2920.03, $2934.49,2965.35$, and $2985.60 \mathrm{~cm}^{-1}$. The spectrum portrayed by intense bands at 3300$2500 \mathrm{~cm}^{-1}$ due to the $\mathrm{O}-\mathrm{H}$ stretching vibration. The characteristic peaks of the drug were also present in the spectrum of optimized formulation. However, some of the drug peaks were slightly shifted or the intensity decreased slightly. These results suggested that there was no interaction between the pure repaglinide and excipients.

\section{$\mathrm{X}$-ray diffraction studies}

The powder X-ray diffraction pattern of the repaglinide and optimized formulation (formulation F1) are illustrated in Figure 5. Pure repaglinide showed various characteristic intense peaks at 2-theta (deg) of 7.6671, $10.1308,12.4531,13.8098,14.637,15.33$, $16.6879,17.5291,18.6227,20.4963,22.5773$, $22.9163,23.9246,26.1468$, and 30.8285 indicating its crystalline nature. The developed GRFS did not show many of the characteristic intense peaks of repaglinide, indicating that the repaglinide in the developed GRFS converted in amorphous form

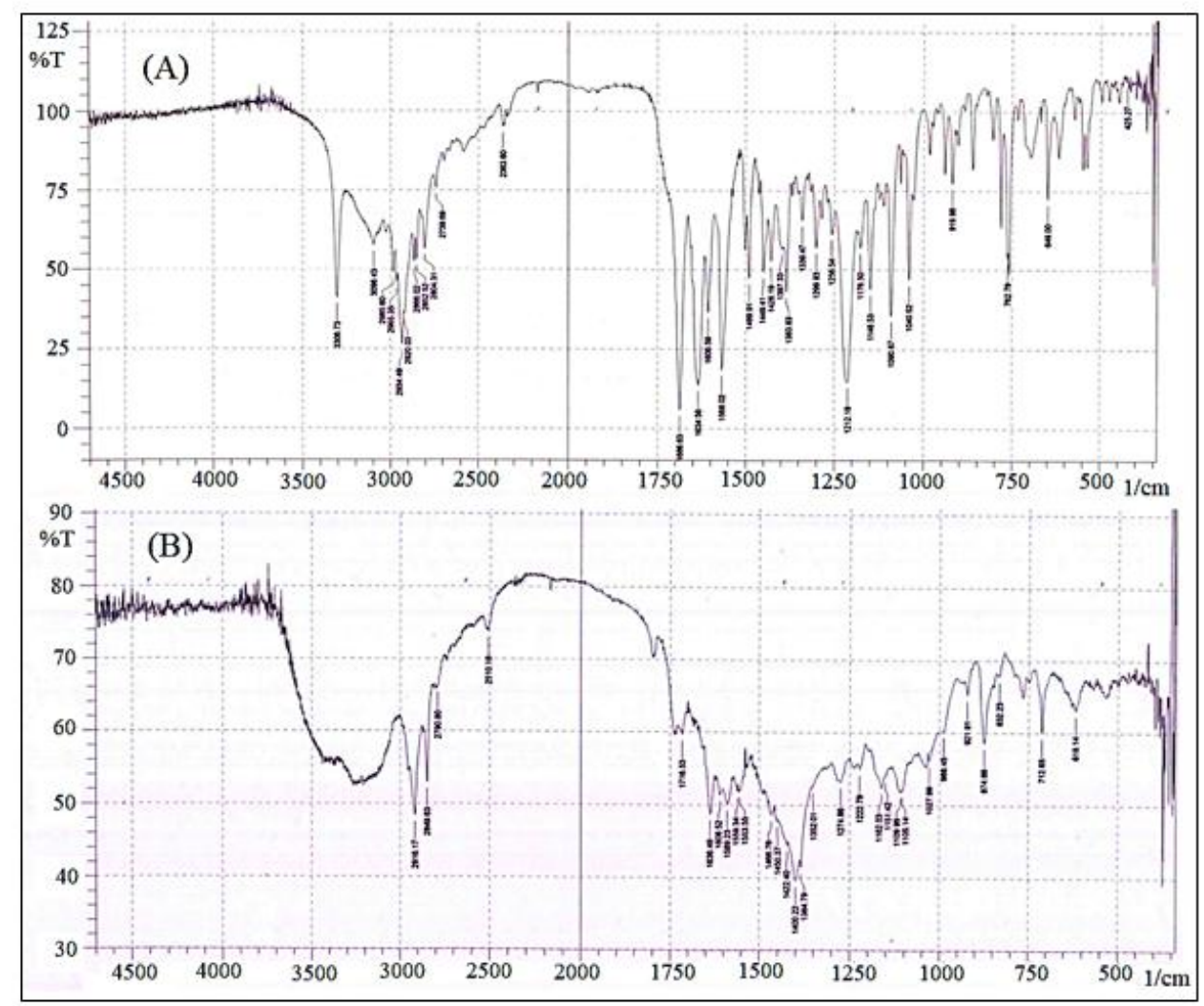

Fig. 4: FTIR of repaglinide (A) and optimized formulation (formulation F1). 


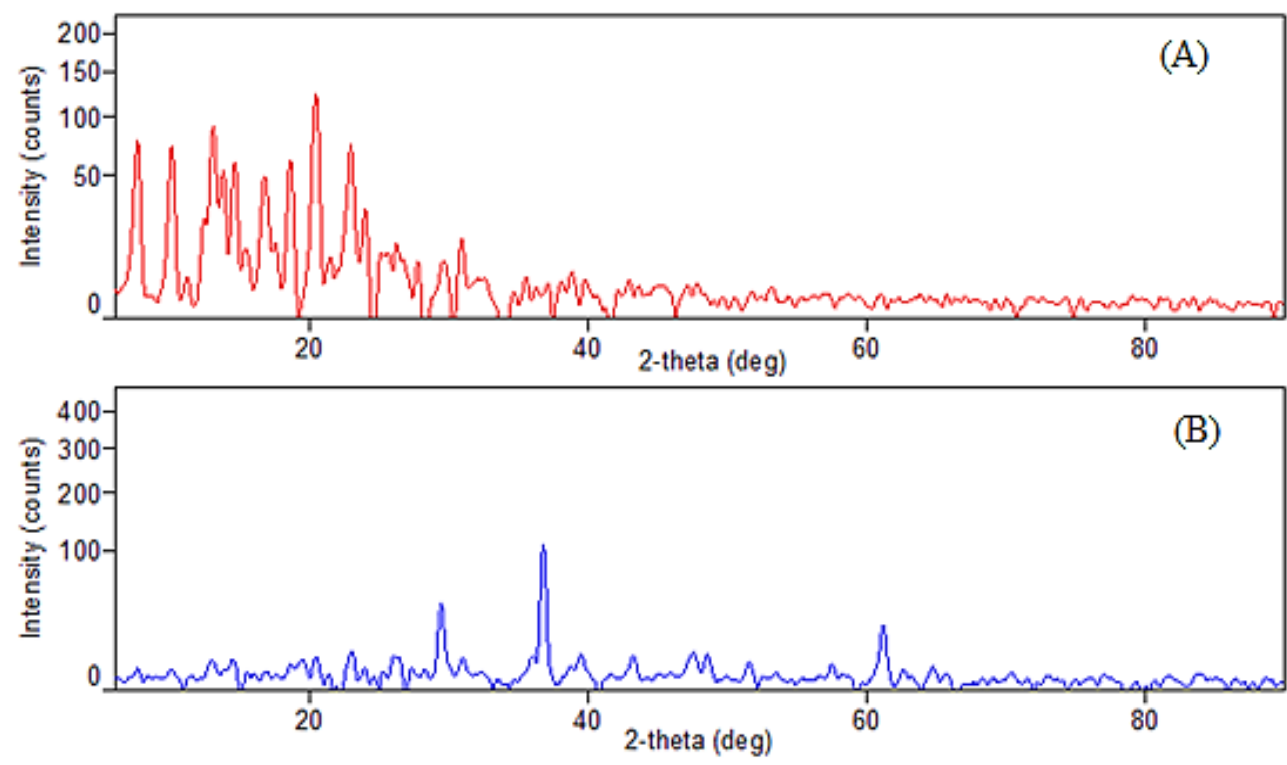

Fig. 5: X-ray diffractograms of pure repaglinide (A) and formulation F1 (B).

\section{Thermal analysis}

DSC thermograms of pure repaglinide, sodium alginate, gellan gum, pectin, and formulation F1 are shown in Figure 6. DSC thermogram of pure repaglinide showed an endothermic peak at $134.26^{\circ} \mathrm{C}$ which was consistent with its melting point. The DSC thermogram of gellan gum exhibited an endothermic peak near $70^{\circ} \mathrm{C}$ and an exothermic peak at $260.41^{\circ} \mathrm{C}$ due to loss of absorbed moisture in sample and polymer degradation, respectively ${ }^{26}$. The endotherm at $188.7^{\circ} \mathrm{C}$ in the thermogram of pectin is due to the thermal degradation of pectin. Sodium alginate showed a broad endotherm and exotherm at $84.0^{\circ} \mathrm{C}$ due to the loss of moisture. The second exothermic peak at $259.2^{\circ} \mathrm{C}$ is due to the loss of volatile components, chain rupture, and fragmentation of sodium alginate ${ }^{17}$. The intensity of endothermic peak of repaglinide the DSC thermograms of repaglinide formulation containing soluble polymer was reduced $\left(134.04^{\circ} \mathrm{C}\right)$ as compared to the pure repaglinide indicating reduce crystallinity of repaglinide and its stabilization in amorphous structure. The reduced intensity of endothermic peak of drug also might be due to dilution effect of different excipients ${ }^{27}$. These results agree with the results of XRD study (Figure 5).

\section{Viscosity Study}

Viscosity is the most important parameter which needs to evaluate for a liquid floating raft forming system that plays an important role in controlling drug release and gastric retention of the formulation. Viscosity results of the formulation F1 (before and after raft formation) are shown in Figure 7. Pectin is recognized as viscosity enhancing agents and approved by US Food and Drug Administration (FDA) and is official in United States Pharmacopoeia (USP). Gellan gum (an excellent gelling polymer) is a natural polysaccharide derived from Pseudomonas elodea, composed of glucuronic acid, rhamnose and glucose, and O-acetyl moieties $^{28}$. These polymers significantly imparted viscosity in the formulations. The viscosity of liquid formulation increased drastically when it formed raft in presence of $0.1 \mathrm{~N} \mathrm{HCl}$ ( $\mathrm{pH} 1.2)$. High viscosity can retard the escape of generated carbon-di-oxide within the polymer metrices and prolonged buoyancy duration. Higher viscosity values can also retard the drug release rate from formulation. 


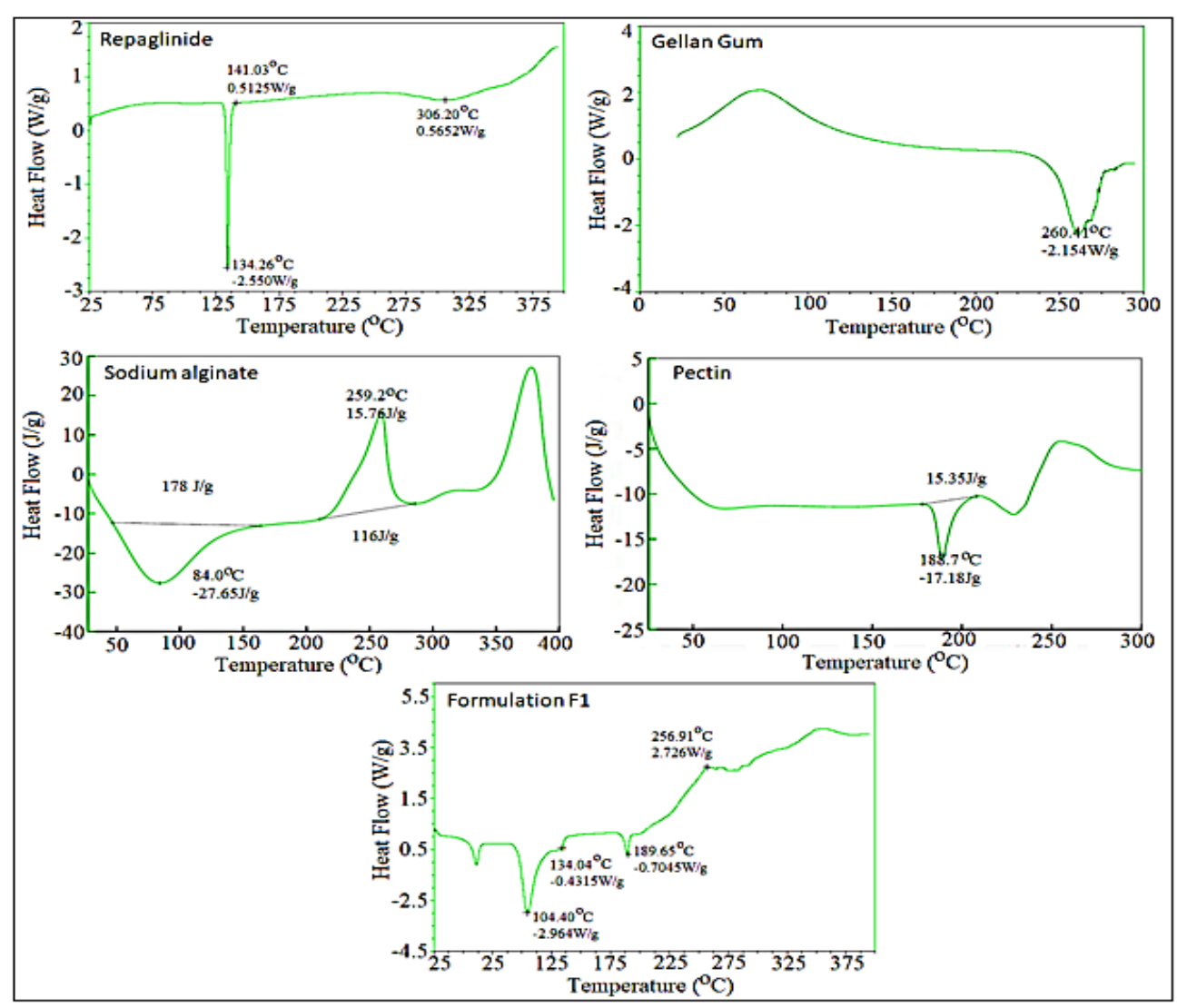

Fig. 6: DSC thermograms of pure repaglinide, sodium alginate, gellan gum, pectin, and formulation F1

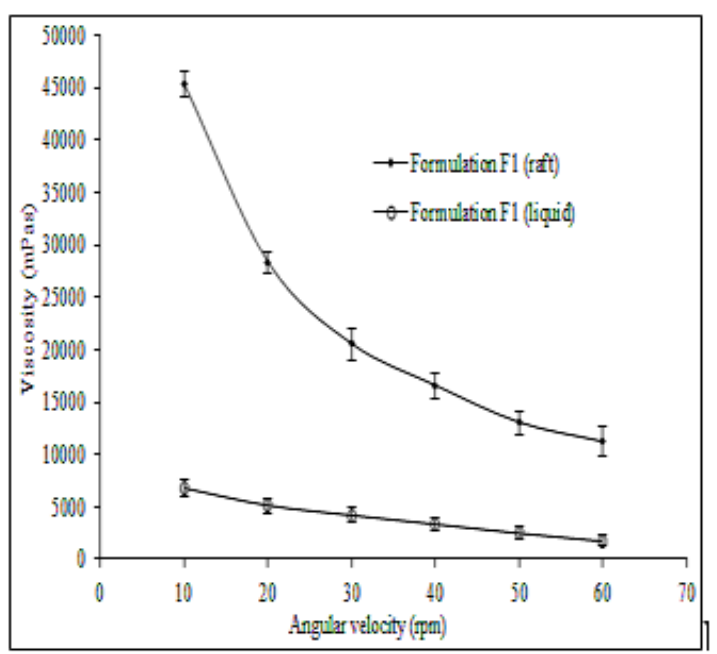

Fig. 7: Viscosity result of formulation F1 (liquid) and formulation F1 (raft) at 10, 20, 30, 40, 50 , and $60 \mathrm{rpm}($ mean $\pm \mathrm{SD}, \mathrm{n}=3)$.

\section{In- vitro drug release studies}

Figure 8 indicates a two-stage repaglinide release profile from the GRFS. The first phase was observed by a slow drug release profile.
The second phase was characterized by a rapid drug release profile. From the formulation $F_{1}$ (containing gellan gum $(500 \mathrm{mg})$, pectin $(500$ $\mathrm{mg}$ ), and GMS (500 $\mathrm{mg})$ ) less than $10 \%$ repaglinide was released within 2 hrs., $21 \%$ of the drug in first $4 \mathrm{hrs}$., $69 \%$ in $6 \mathrm{hrs}$., and reached $97 \%$ in $7 \mathrm{hrs}$.. In the case of formulation F2, where gellan gum was not present, the drug release was 35\% in the first 2 hrs. and reached $90 \%$ in $4 \mathrm{hrs}$. In formulation F3, where the concentration of gellan gum, pectin and GMS is half than that of formulation F1 i.e., $250 \mathrm{mg}$ each of gellan gum, pectin and GMS, the drug released was $14 \%$ in the first 2 hrs., $31 \%$ in 4 hrs. and $91 \%$ in 6 hrs. Sodium citrate complexes the free $\mathrm{Ca}^{2+}$ ions and only releases them in the acidic environment of the stomach. The cross-linking of polymer network and its gelation due to the $\mathrm{Ca}^{2+}$ ions occurred in acidic environment ${ }^{18 \& 19 \& 29}$. These results suggested that the sodium citrate and polymers had a significant effect on drug release profile. 


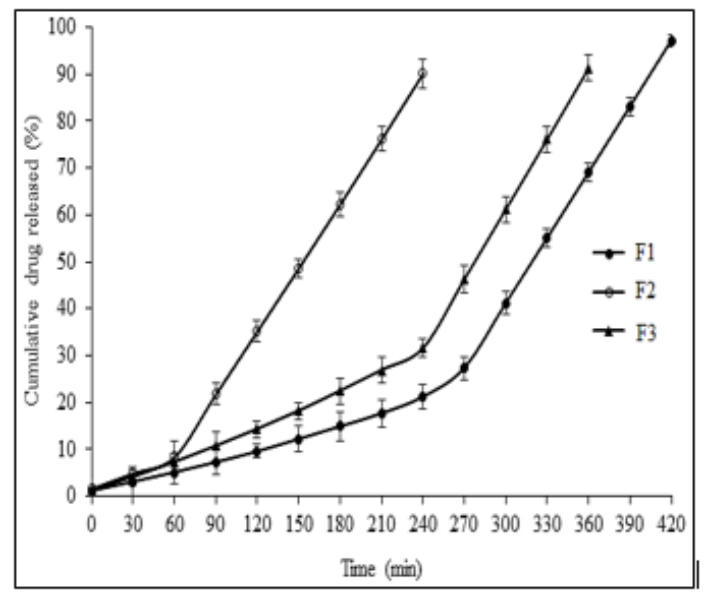

Fig. 8: In-vitro drug release profiles of formulation F1, F2, F3 of liquid GRFS containing repaglinide (filled circles $\mathrm{F} 1$, empty circles $\mathrm{F} 2$, and filled triangles $\mathrm{F} 3)$ in $0.1 \mathrm{~N} \mathrm{HCl}(\mathrm{pH}$ $1.2)$ at $37^{\circ} \mathrm{C}($ mean $\pm \mathrm{SD}, \mathrm{n}=3)$.

The release data of repaglinide from GRFS was analysed using the zero order (Cumulative amount of percentage drug released against time) and first order (log percentage cumulative drug remaining against time) plots. Confirmation of the order of release was carried out using Higuchi's model (a plot of the cumulative percentage of drug released versus square root of time). To determine drug release mechanism and to verify the fact that whether diffusion is nonFickian or Fickian, the slope (n) values were analysed according to Peppas' model (log cumulative percentage of drug release was plotted against log time). The $\mathrm{n}$ value less than or equal to 0.5 indicates diffusion controlled drug release without swelling. The $\mathrm{n}$ value between 0.5 and 1 indicates the drug release through diffusion with swelling. If the $n$ value is more than 1, it indicates anomalous diffusion (non-Fickian). The linearity of the plots was confirmed by the calculation of correlation coefficient $\left(\mathrm{r}^{2}\right)^{14}$. The best fitting of models was based on goodness of fit i.e. the highest $\mathrm{r}^{2}$. The results confirmed that the repaglinide dissolution from GRFS followed zero order kinetcs (Table 3). The Higuchi's plots showed linearity with correlation coefficient $\left(\mathrm{r}^{2}\right)$ values between 0.8653 and 0.9907 . The diffusion mechanism of drug release was further confirmed by Peppas' plots that showed linearity for repaglinide release from GRFS $\left(\mathrm{r}^{2}\right.$ values between 0.9196 and 0.9898 with slope (n) values between 0.1113 and 0.1806), indicating diffusion-controlled drug release from the GRFS without swelling (Table 3).

On application of two-way ANOVA, the calculated $F$ value was higher than the tabulated value indicating a significant difference in the in-vitro release profiles among formulation $\mathrm{F} 1, \mathrm{~F} 2$, and $\mathrm{F} 3$ at $95 \%$ confidence interval $(p<0.001)$. This substantiates the role of polymers and sodium citrate in controlling drug release from GRFS (Table 4).

Table 3 : Results of kinetic study of repaglinide release from GRFS in $0.1 \mathrm{~N} \mathrm{HCl}(\mathrm{pH} 1.2)$

\begin{tabular}{|c|c|c|c|c|c||}
\hline \multirow{2}{*}{ Formulation code } & \multicolumn{3}{|c|}{ Model } \\
\cline { 2 - 6 } & Zero order & First order & Higuchi's model & \multicolumn{2}{c||}{ Peppas' model } \\
\cline { 2 - 6 } & $\mathrm{r}^{2}$ & $\mathrm{r}^{2}$ & $\mathrm{r}^{2}$ & $\mathrm{r}$ \\
\hline Formulation F1 & 0.8558 & 0.5793 & 0.8653 & 0.9898 & 0.1113 \\
\hline Formulation F2 & 0.9784 & 0.8469 & 0.9907 & 0.9196 & 0.1806 \\
\hline Formulation F3 & 0.8906 & 0.6827 & 0.8944 & 0.9811 & 0.1148 \\
\hline
\end{tabular}

$r^{2}$ is correlation coefficient, $n$ is the slope

Table 4. Results of ANOVA on the release profiles of repaglinide from GRFS in $0.1 \mathrm{~N} \mathrm{HCl}(\mathrm{pH} 1.2)$

\begin{tabular}{||l|c|c|c|c|c||}
\hline \multicolumn{1}{|c|}{ Source of variation } & $\begin{array}{c}\text { Sum of } \\
\text { square }\end{array}$ & $\begin{array}{c}\text { Degree of } \\
\text { freedom }\end{array}$ & $\begin{array}{c}\text { Mean } \\
\text { squares }\end{array}$ & $\begin{array}{c}\text { Calculated F } \\
\text { (DFn, DFd) }\end{array}$ & P value \\
\hline Raw sum of squares & 86860 & 14 & 6204 & $\mathrm{~F}(14,93)=48.31$ & $\mathrm{P}<0.0001$ \\
\hline Column sum of squares & 13537 & 2 & 6768 & $\mathrm{~F}(2,93)=52.70$ & $\mathrm{P}<0.0001$ \\
\hline Error sum of squares & 11944 & 93 & 128.4 & & \\
\hline
\end{tabular}




\section{Conclusion}

A liquid in-situ raft forming floating system for repaglinide was successfully developed. This liquid formulation can be easily gulped and quickly changed to a floating gel raft in the stomach. This liquid system is expected to provide clinicians with a safe choice of product for better control of blood sugar level. The formulation showed excellent buoyancy coupled with extended drug release from a hydrophilic matrix. The type and amount of polymer played the main role in invitro performance of the formulation. Buoyancy lag time increased with an increase in polymer concentration. Best drug release profile was obtained from formulation containing gellan gum $(500 \mathrm{mg})$, and pectin $(500 \mathrm{mg}$ ) in combination in presence of GMS $(500 \mathrm{mg})$. The developed liquid floating formulation showed promising results in the preliminary laboratory tests. However, scale up studies and biopharmaceutical characterization are needed to establish these formulations.

\section{REFERENCES}

1. S. Jindal, K. Jindal, G. D. Gupta, R. Garg and R. Awasthi "Gastroretentive floating tablets: An investigation of excipients effect on tablet properties", Marmara Pharm J, 20(2), 100-110 (2016).

2. H. Reza Rezaie, M. Esnaashary, A. Aref arjmand and A. Ochsner "Controlled Drug Delivery Systems", In: A Review of Biomaterials and Their Applications in Drug Delivery, Springer, Singapore, 2018.

3. V.K. Pawar, S. Kansal, G. Garg, R. Awasthi, D. Singodia and G. T. Kulkarni "Gastroretentive dosage forms: A review with special emphasis on floating drug delivery systems", Drug Deliv, 18(2), 97110 (2011).

4. R. Awasthi, V. Pawar and G. T. Kulkarni "Floating microparticulate systems: an approach to increase gastric retention", Ind J Pharm, 1(1), 17-26 (2010).

5. R. Awasthi, G.T. Kulkarni, V. K. Pawar and G. Garg (2012), "Optimization studies on gastroretentive floating system using response surface methodology", AAPS PharmSciTech, 13(1), 85-93 (2010).

6. S. Khatri and R. Awasthi "Piperine containing floating microspheres: an approach for drug targeting to the upper gastrointestinal tract", Drug Deliv Transl Res, 6(3), 299-307 (2016).

7. R. Awasthi and G. T. Kulkarni "Decades of research in drug targeting to the upper gastrointestinal tract using gastroretention technologies: where do we stand?", Drug Deliv, 23(2), 378-394 (2016).

8. M.U. Kumar, B. Chatterjee and F. G. Senjoti "Gastro-retentive drug delivery systems and there in vivo success: a recent update", Asian J Pharm Sci, 11(5), 575584 (2016).

9. N. Sharma and R. Awasthi "Development and characterization of novel gastroretentive raft forming floating film of atenolol", Indian Drugs, 52(3), 15-23 (2015).

10. A. Makwana, K. Sameja, H. Parekh and Y. Pandya "Advancements in controlled release gastroretentive drug delivery system: A review", J Drug Del Ther, 2(3), 12-21 (2012).

11. V. D. Prajapati, G. K. Jani, T. A. Khutliwala and B. S. Zala "Raft forming system- An upcoming approach of gastroretentive drug delivery system", $\boldsymbol{J}$ Control Release , 168(2), 151-165 (2013).

12. N. Kerdsakundee, S. Mahattanadul and R. Wiwattanapatapee "Development and evaluation of gastroretentive raft forming systems incorporating curcumin Eudragit $^{\circledR}$ EPO solid dispersions for gastric ulcer treatment", Eur J Pharm Biopharm, 94, 513-520 (2015).

13. R. Awasthi and G.T. Kulkarni "Development and characterization of amoxicillin loaded floating microballoons for the treatment of Helicobacter pylori induced gastric ulcer", Asian J Pharm Sci, 8(3), 174-180 (2013).

14. R. Awasthi and G. T. Kulkarni "Development of novel gastroretentive drug delivery system of gliclazide: hollow beads", Drug Dev Ind Pharm, 40(3), 398408 (2014).

15. J. A. Balfour, D. Faulds, "Repaglinide". Drugs and Aging, 13(2), 173-180 (1998).

16. G. L. Plosker, D. P. Figgitt, "Repaglinide", PharmacoEconomics, 22, 389-411 (2004).

17. R. Awasthi, G.T. Kulkarni, M.V. Ramana, T. D. Pinto, I. S. Kikuchi, D. D. Ghisleni, 
M. de Souza Braga, P. De Bank and K. Dua, "Dual crosslinked pectin-alginate network as sustained release hydrophilic matrix for repaglinide", Int $\boldsymbol{J}$ Biol Macromol, 97, 721-732 (2017).

18. S. M. Abouelatta, A. A. Aboelwafa and O. N. El- Gazayerly "Gastroretentive raft liquid delivery system as a new approach to release extension for carrier-mediated drug", Drug Deliv, 25(1), 1161-1174 (2018).

19. N.A. Abou Youssef, A.A. Kassem, M.A. EI-Massik and N. A. Boraie "Development of gastroretentive metronidazole floating raft system for targeting Helicobacter pylori", Int J Pharm, 486(1-2), 297-305 (2015).

20. P.S. Rajinikanth and B. Mishra "Floating in-situ gelling system for stomach site specific delivery of clarithromycin to eradicate H. pylori", J Control Release, 125(1), 33- 41 (2008).

21. A. Streubel, J. Siepmann, R. Bodmeier "Multiple unit gastroretentive drug delivery systems: a new preparation method for low density microparticles", $\boldsymbol{J}$ Microencapsul, 20 (3), 329-347 (2003).

22. M. H. Teaima, M.M. Abdel Hamid, N.A. Shoman, B.R. Jasti, M.A. EI- Nabarawi and M. Yasser "Formulation, Characterization and comparative pharmacokinetic study of bupropion floating raft system as a promising approach for treating depression", $\boldsymbol{J}$ Pharm Sci, 109(11), 3451-3461 (2020).
23. R. Awasthi and G. T. Kulkarni "Development of novel gastroretentive floating particulate drug delivery system of gliclazide", Curr Drug Deliv, 9(5), 437-451 (2012).

24. R. Awasthi and G.T. Kulkarni "Concentration dependent rheological behavior of different grades of pectin", $\boldsymbol{J}$ Pharm Res, 3(8), 1926-1929 (2010).

25. R. Awasthi "Selection of pectin as pharmaceutical excepient on the basis of rheological behavior", Int J Pharm Pharm Sci, 3(1), 229-231 (2011).

26. S. Agnello, L. Gasperini, J.F. Mano, G. Pitarresi, F.S. Palumbo, R.L. Reis and G. Giammona "Synthesis, mechanical and thermal rheological properties of new gellan gum derivatives", Int J Biol Macromol, 98, 646-653 (2017).

27. M.A. Molaei, K. Osouli-Bostanabad, K. Adibkia, J. Shokri, S. Asnaashari and Y. Javadzadeh "Enhancement of ketoconazole dissolution rate by the liquisolid technique", Acta Pharmaceutica, 68(3),325-336 (2018).

28. K. Prakash, V. M. Satyanarayana, H. T. Nagiat, A. H. Fathi, A. K. Shanta and A.R. Prameela "Formulation development and evaluation of novel oral jellies of carbamazepine using pectin, guar gum, and gellan gum", Asian J Pharm, 8(4), 241-249 (2014).

29. M. Marudova and N. Jilov "Influence of sodium citrate and potassium-sodium tartrate on gelation of low-methoxyl amidated pectin", J Food Eng, 59(2-3), 177-180 (2003). 


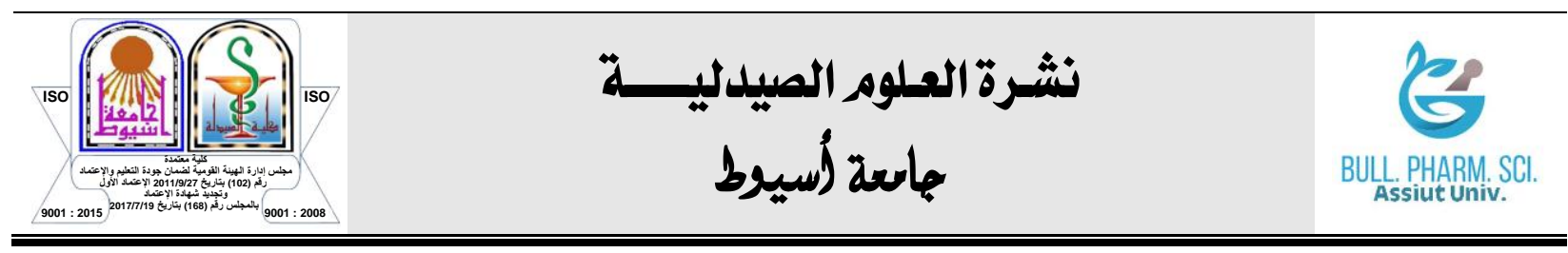

\section{تكون نظام سائل مد بالاواء طاف على سطح المحتوى المعوى يحتوى على عقار

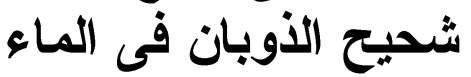$$
\text { فيثالى جوشى - راجندرا أواستي }
$$

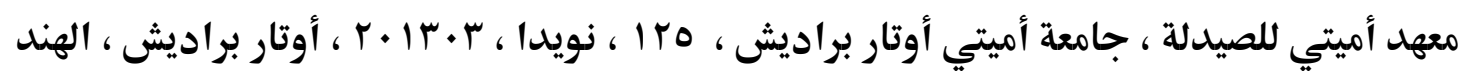

تم فى هذا البحث تطوير نظام داخلى طاف عل سطح المحتوى المعوى لعقار الريباجلينيل باستخدام

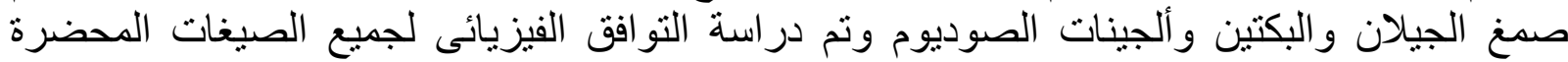

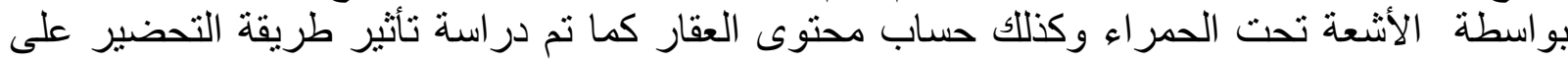
حالة العقار بو اسطة حيود الأشعة السينية و الماسح الحرارى التفاضلى وكذللك إنطلاق العقار من الصيات الصياغات المحضرة معمليا

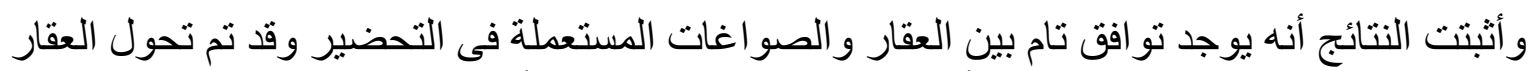

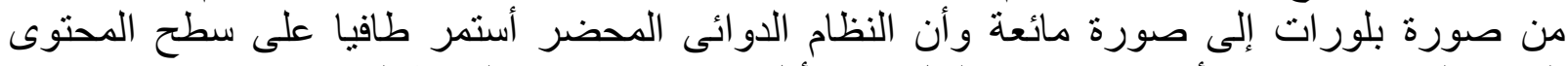

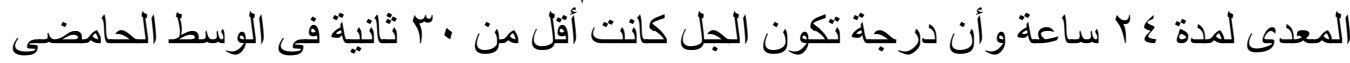

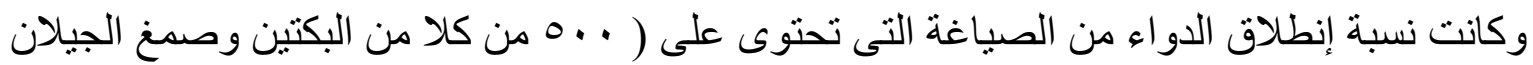

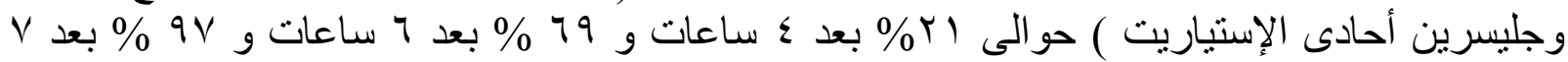

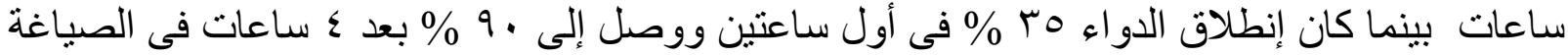
التى لا تحتوى على صمغ الجيلان وبناء على النتائج السابقة توصلت الدراسة إلى إنه بتحضير سائل يتحول إلى إلى جيل على سطح المحتوى المعوى كنظام ممد بالدو اء يمكن زيادة الذائبية للعقار ات شحيحة الذوبان النيان فى الماء 